\title{
Role of Sea Surface Salinity Feedback in MJO Predictability: A Study with CFSv2
}

\author{
JIESHUN ZHU \\ Earth System Science Interdisciplinary Center, University of Maryland, and NOAA/NWS/NCEP/Climate Prediction \\ Center, College Park, Maryland
}

ARUN KUMAR

NOAA/NWS/NCEP/Climate Prediction Center, College Park, Maryland

(Manuscript received 2 November 2018, in final form 30 May 2019)

\begin{abstract}
While previous studies suggested that salinity could feed back onto MJO variability via modulating upper ocean stratification and further on SST, there is no direct evidence yet proving (or disproving) the importance of this feedback in MJO evolution and its predictability. This study is an initial attempt to quantify the role of SSS feedback on MJO predictability, based on a "perfect model" framework with the CFSv2. Specifically, the SSS feedback is isolated by nudging model SSS to climatological states during forecasts. For comparison, two more experiments were done, one as a benchmark experiment by estimating MJO predictability in CFSv2 and another one for estimating the role of SST feedback. Analyses of these experiments indicate that SSS feedback exerts negligible influences on MJO predictability within the constraints of the model, in contrast to significant impacts from SST feedback. Further analysis showed that a lack of SSS influence in MJO predictability can be attributed to marginal changes in SST associated with the SSS nudging. However, there is a caveat to the conclusion about SSS feedback. Because the barrier layer (BL) acts as a "bridge" for possible SSS influences on SST over the tropical Indian and western Pacific oceans, its simulation in CFSv2 is further explored. Analyses indicate that, in spite of realistic simulations of the MJO and intraseasonal SSS variability in CFSv2, significant BL simulation biases are present in the tropical oceans, including too thin a climatological thickness, too small intraseasonal variations, and an unrealistic intraseasonal BL-SST relationship. Thus, our predictability experiments cannot reject the hypothesis that SSS does play a role in MJO predictability; it is possible that biases in CFSv2 influence its ability to capture such signals.
\end{abstract}

\section{Introduction}

Ocean salinity is a fundamental physical property of seawater, which influences the stratification and circulation of the world oceans. It also serves as a potential indicator of the global water cycle (e.g., Schmitt 2008). In basins where the upper ocean stratification is primarily controlled by salinity, the density mixed layer depth is shallower than the isothermal layer depth, and the barrier layer (BL) exists between the base of the mixed layer defined based on density and the thermocline (Lukas and Lindstrom 1991; Sprintall and Tomczak 1992). In the tropical oceans, climatological BL generally exists wherever rainfall is pronounced in a climatological sense [e.g., the intertropical convergence zone (ITCZ)

\footnotetext{
Corresponding author: Jieshun Zhu, jieshun@umd.edu
}

and the South Pacific convergence zone (SPCZ)] (Sprintall and Tomczak 1992).

The BL can affect sea surface temperature (SST) via several mechanisms. In the presence of a BL, incoming fluxes of heat and freshwater can be trapped within the mixed layer, reducing their influence on the thermocline while enhancing on surface temperature and salinity. Similarly, by trapping momentum mixing from winds, the BL can also enhance surface currents and, hence, horizontal advection. In addition, the presence of the BL reduces the vertical temperature gradient at the base of the mixed layer, and therefore can shut off turbulent entrainment of cooler water that usually occurs when the mixed layer deepens, thus decoupling the dynamic and thermodynamic drivers of the surface ocean thermal inertia.

The role of salinity in seasonal-to-interannual variability has been addressed in models (e.g., Murtugudde 
and Busalacchi 1998; Ballebrera-Poy et al. 2002; Delcroix and McPhaden 2002). The relationships among salinity variability, freshwater fluxes, and the barrier layer variability, and the potential feedbacks among them are noted in various studies at interannual time scales (Murtugudde and Busalacchi 1999; Murtugudde et al. 2002; Hendon 2003; Hu and Sprintall 2016). Particularly, studies suggest that salinity, via the modulation of the BL in the Indo-Pacific regions, could influence the evolution of important climate modes, such as the Asian monsoon (e.g., Seo et al. 2009), Indian Ocean dipole (e.g., Annamalai et al. 2003; Masson et al. 2003; Qiu et al. 2012), and El Niño-Southern Oscillation (ENSO; e.g., Picaut et al. 1996; Maes et al. 2005; Zhu et al. 2014). Zhu et al. (2014), based on experiments with the CFSv2, found that salinity played an active role in the evolution of the 2007/08 La Niña event, and its initialization was vital for the predictions starting from spring. They further suggested that the near-surface salinity anomalies over the salinity front at the western Pacific warm pool eastern edge (WPEE) were vital for the La Niña development.

It has also been argued that larger-than-expected changes could occur in the ocean when winds blow over the salinity front (Cravatte et al. 2016). For example, the salinity front could interact with westerly wind events, which are typically associated with a Madden-Julian oscillation (MJO) event and are important during the initiation and development phase of ENSO (e.g., Lengaigne et al. 2004; McPhaden 2004). The westerlies force surface-intensified eastward currents that tilt the salinity front near the eastern edge, creating a barrier layer (Cronin and McPhaden 2002). This shallow salinity-stratified mixed layer, in turn, can trap wind-input momentum in a thin surface layer and amplify the surface eastward jet (Roemmich et al. 1994). This interaction maintains and lengthens the zonal extent of warm SST, fostering an environment for additional westerly winds that extend the WPEE farther east, triggering the Bjerknes feedback that acts to further intensify a developing El Niño.

At the intraseasonal time scale, the availability of Argo profiles and global data from the satellite salinity missions [e.g., Aquarius (Lagerloef et al. 2010) and SMOS (Font et al. 2013)] have begun to yield new insights into salinity variability (e.g., Matthews et al. 2010; Grunseich et al. 2013; Drushka et al. 2012, 2014; Guan et al. 2014). The observational studies are also complemented by forced ocean simulation experiments (e.g., Li et al. 2015; Li and Han 2016). Despite some inconsistencies in inferring the role of ocean dynamics versus the effect of evaporationminus-precipitation $(E-P)$ on salinity variability, these studies have found significant modulation of surface and upper ocean salinity by the MJO.
The feedback of salinity onto MJO variability, however, has only been indirectly suggested via its role in upper ocean stratification variability (e.g., the BL), and further by modulating intraseasonal SST (e.g., Zhang and McPhaden 2000; Drushka et al. 2014; Guan et al. 2014; Horii et al. 2016). For example, Drushka et al. (2014) evaluated the effect of the BL on the upper ocean response to $\mathrm{MJO}$ forcing in the eastern equatorial Indian Ocean (e.g., $0^{\circ}, 90^{\circ} \mathrm{E}$ ) and found that modulation of the BL can have significant consequences on the response of the upper ocean to the MJO with a thicker BL corresponding to weaker SST anomalies. For the western tropical Pacific (e.g., $\left.0^{\circ}, 165^{\circ} \mathrm{E}\right)$, the composite analysis by Zhang and McPhaden (2000) suggests that the intraseasonal surface cooling was partially contributed by thinning of BL. Guan et al. (2014) also suggested that the MJO-related salinity anomalies could strongly regulate surface density and potential energy. As the mean SST in the warm pool region is close to the threshold of atmospheric convection, any small SST fluctuations may significantly modulate the potential for local convective activity. Therefore, the above studies imply that the MJO-related salinity (and BL) variations might be able to feed back onto the MJO itself through their influence on SST. As a matter of fact, the role of the BL in the MJO was stated as one of three hypotheses to be tested by the Dynamics of the Madden-Julian Oscillation (DYNAMO; Yoneyama et al. 2013) field campaign.

As far as we know, there is no direct evidence so far that proves or disproves the role of salinity (or the BL) in MJO evolutions. In this study, the NCEP CFSv2 (Saha et al. 2014) is used to assess MJO predictability experiments to validate the possible role of sea surface salinity (SSS) feedback, in which the model SSS is nudged to a climatological state during integrations and the SSS feedback is thus suppressed. The hypothesis to be tested with the experiments is that the variations in SSSs over the tropical Indian and western Pacific Oceans might modulate the local BL thickness, which may in turn influence the local SST variability and, as a consequence, the MJO predictability.

The paper is organized as follows: The model, experimental design, observations, and analysis methods are described in the section 2. Section 3 briefly examines the MJO simulations in CFSv2, particularly its simulated intraseasonal SSS variability. The MJO predictability results are presented in section 4 . Section 5 further makes some discussions in association with the BL simulation biases in CFSv2. A brief summary is given in section 6 . 


\section{Model, experiments, and analysis methods}

\section{a. Model}

In this study, the NCEP Climate Forecast System, version 2 (CFSv2; Saha et al. 2014), is used for experiments. The ocean component (the GFDL MOM version 4) of CFSv2 has a horizontal grid of $0.5^{\circ} \times 0.5^{\circ}$ poleward of $30^{\circ} \mathrm{S}$ and $30^{\circ} \mathrm{N}$ with meridional resolution gradually increasing to $0.25^{\circ}$ between $10^{\circ} \mathrm{S}$ and $10^{\circ} \mathrm{N}$. Vertically, it has 40 geopotential $(z)$ levels (27 of them in the upper $400 \mathrm{~m}$ ), and its maximum depth is approximately $4.5 \mathrm{~km}$. The atmospheric component of CFSv2 has a horizontal resolution at T126 with 64 vertical levels in a hybrid sigma-pressure coordinate. The two components exchange surface momentum, heat, and freshwater fluxes, as well as SSTs, every $30 \mathrm{~min}$.

There is one difference, however, between the CFSv2 used in this study and the operational CFSv2 (Saha et al. 2014). In the latter, the simplified Arakawa-Schubert (SAS) cumulus parameterization (Pan and Wu 1995) was used as its convection scheme, whereas in this study the relaxed Arakawa-Schubert (RAS) cumulus convection scheme (Moorthi and Suarez 1992,1999) is used. Our previous analyses (Zhu et al. 2017) indicate that the MJO simulation in the CFSv2 with the RAS scheme is quite realistic, and is significantly better than the operational CFSv2 (Saha et al. 2014). In addition, the MJO predictability was also found to be higher in the CFSv2 with RAS (Zhu et al. 2019, manuscript submitted to J. Climate). In following discussion, the CFSv2 version with the RAS scheme is also referred to as CFSv2 for brevity.

\section{b. Experiments}

The predictability experiments in this study are based on a "perfect model" framework. CFSv2 is first integrated for 30 years (Zhu et al. 2017), starting from the Climate Forecast System Reanalysis (CFSR; Saha et al. 2010) initial state on 1 January 1980. After 10 years of integrations, restart files of the free run were saved daily for ocean (and sea ice) and every $12 \mathrm{~h}$ for atmosphere (and land). Based on these restart files, three sets of prediction experiments (referred to as CTL, SST1dy, and SSS1dy) were done. All prediction experiments were for the boreal winters of the second 10 -yr model simulations (referred to as "Reference"). For each experiment, 45-day predictions were made every five days starting from 1 November of each of the 10 model years until the end of following March (totally, 31 cases for each winter), with five ensemble members applied. The five ensemble members were generated by perturbing the atmospheric initial conditions saved during the free run, that is, by adding a small fraction $(1 \%-3 \%)$ of atmospheric state differences between current time and $12 \mathrm{~h}$ ahead/behind to the initial conditions. For each of the three prediction experiments, there are a total of 10 years $\times 31$ cases $\times 5$ members $(=1550) 45$-day predictions.

In CTL, the prediction model was CFSv2 itself and the initial conditions were constructed from restart files saved during the free run (with the generation of five ensemble members as described above). CTL is conducted to benchmark the MJO predictability in CFSv2. In SST1dy (SSS1dy), all model settings and initializations are same as in CTL, except that model SSTs (SSSs) during integrations are nudged to model climatological SSTs (SSSs) with a seasonal cycle. The model climatologies were derived from the free run. For the choice of restoring time scale of 1 day, the SST (SSS) feedback is strongly suppressed in the prediction experiments of SST1dy (SSS1dy). We note that in the SSS1dy experiments, SST and MJO feedback still occurs; however, the role SSS may play in this feedback (via modulating SSTs) is suppressed. Considering that the possible effect of SSS on MJO must be bridged through SST, and if all the SST variability (in the context of MJO) was due to SSS, the SST1dy experiment is the upper limit of skill degradation if SSS variability was suppressed (i.e., the SSS1dy simulation).

\section{c. Observations}

To validate the property of simulated MJOs in CFSv2, the following observational data were used: daily SST analyses from the National Centers for Environmental Information (NCEI) using the optimum interpolation (OI) scheme (Reynolds et al. 2007); rainfall estimate from the $\mathrm{CPC}$ morphing technique (CMORPH) satellite retrieval (Joyce et al. 2004); 850$\mathrm{hPa}$ zonal winds (U850) from the CFSR (Saha et al. 2010); and daily SSS data of the Level 3 version 2 Aquarius Combined Active-Passive (CAP) product (Yueh 2013; https://podaac.jpl.nasa.gov/aquarius). The observed MJO events are tracked based on the commonly used Real-time Multivariate MJO (RMM) index (Wheeler and Hendon 2004), and the daily index values, including the phase and magnitude of the MJO, are obtained from the Center for Australian Weather and Climate Research. Most validations are based on data during January 1998-December 2014, except for SSS data, which are for August 2011-June 2015 (the Aquarius record period; Lagerloef et al. 2010). In addition, the climatological BL thickness produced by French Research Institute for Exploration of the Sea (IFREMER; http://www.ifremer.fr/cerweb/deboyer/mld/ Subsurface_Barrier_Layer_Thickness.php) is taken as observations. 
Composite MJO lifecycle

(a) OBS: Prate(shaded) and U850(contour)

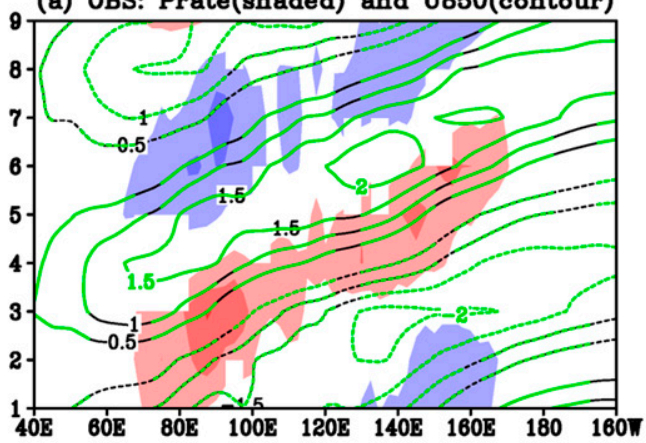

(c) CFSv2RAS: Prate(shaded) and U850(contour)

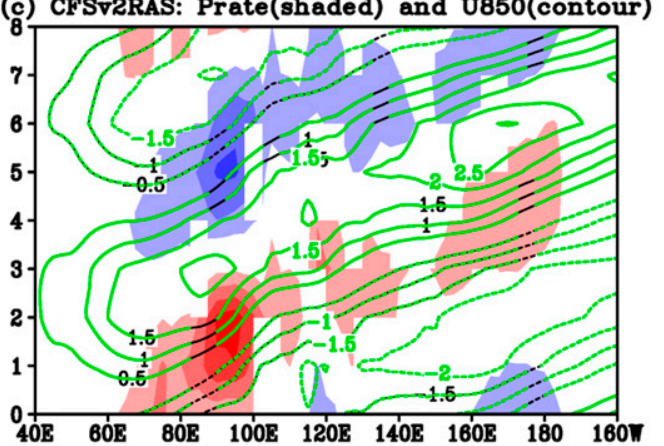

(b) OBS: Prate(shaded) and SST (contour)

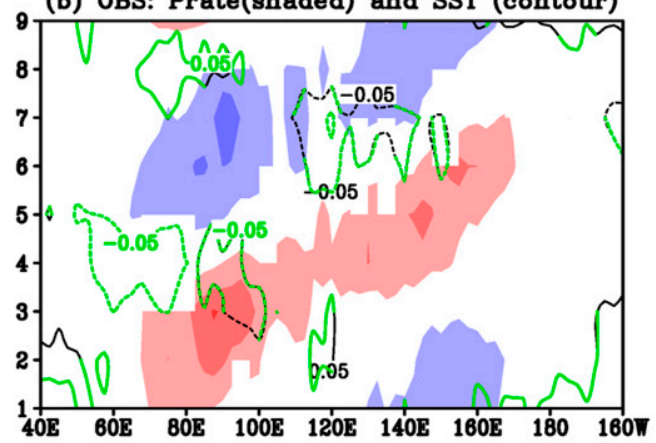

(d) CFSv2RAS: Prate(shaded) and SST (contour)

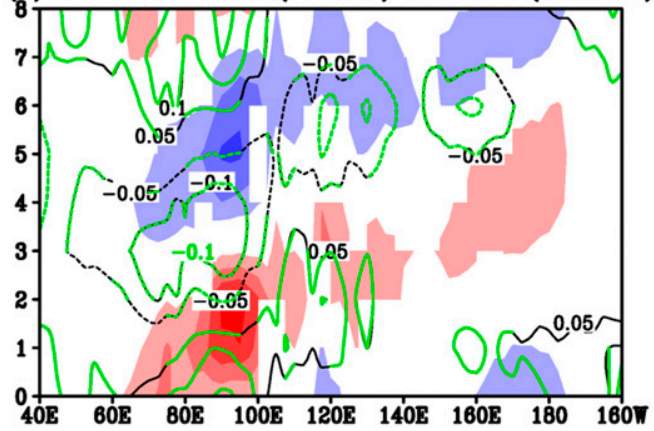

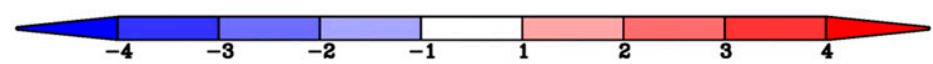

FIG. 1. Composite MJO life cycle in (a),(b) observations and (c),(d) CFSv2RAS for intraseasonal anomalies of (a),(c) precipitation (mm day ${ }^{-1}$; shadings) and U850 ( $\mathrm{m} \mathrm{s}^{-1}$; contours) and (b),(d) precipitation (mm day ${ }^{-1}$; shadings) and SST $\left({ }^{\circ} \mathrm{C}\right.$; contours). For each phase, the composite value is the average of the days when the MJO is in a particular phase and the MJO amplitude is greater than 1, which in observations (CFSv2RAS) ranges from 409 days for phase 7 (476 days for phase 6) to 523 days for phase 1 (558 days for phase 8). The $y$ axis represents MJO phases. Phase 1 (phase 8 ) is repeated as phase 9 (phase 0) in observations (CFSv2RAS) for continuity of the display. Values in shadings and in green contours are significant at the $90 \%$ level based on a two-tailed Student $t$ test.

\section{d. Analysis methods}

For the validation of CFSv2, the daily anomalies of observed fields are calculated as departures from seasonal climatology, which is defined as annual mean plus the first four harmonics of long-term average over 2012-14 for Aquarius SSS and 1998-2014 for other variables. The intraseasonal anomalies are further obtained by applying $20-100$-day bandpass filtering to the raw daily mean anomalies. A similar procedure is used for calculating the intraseasonal anomalies of model fields for the last 20 years of the above 30 -yr free run with CFSv2. Composite analysis is used to derive MJOrelated variations for both observed and simulated fields, and its statistical significance is evaluated based on two-tailed Student $t$ test.

To extract the MJO component in CFSv2, a process similar to that in Wheeler and Hendon (2004) is adopted. Specifically, a combined empirical orthogonal function (EOF) analysis is done for the equatorially (between $15^{\circ} \mathrm{S}$ and $15^{\circ} \mathrm{N}$ ) averaged model outgoing longwave radiation (OLR), and $850-$ and $200-\mathrm{hPa}$ zonal wind (U850 and U200) filtered anomalies, which are first normalized by their respective standard deviation. The first two leading EOFs (not shown) are taken as a representation of the MJO in CFSv2, and their corresponding normalized principal components ( $\mathrm{PC} 1$ and $\mathrm{PC} 2)$ are used to define its amplitude $\left(\mathrm{MJO}_{\mathrm{amp}}=\sqrt{\mathrm{PC}^{2}+\mathrm{PC}^{2}}\right)$ and phase angle $\left\{\mathrm{MJO}_{\text {pha }}=\tan ^{-1}[(-\mathrm{PC} 1) / \mathrm{PC} 2]\right\}$.

The reference and predicted MJO indices are obtained by projecting the Reference and predicted anomalous fields onto the above two EOF modes. The predicted field anomalies are obtained by removing a background that is a function of starting date and lead day. The background is computed as a fourth-order polynomial fit over the 31 5-day periods (corresponding to 155 days) for each year and each 


\section{Standard Deviation of SSS Anomalies}

(a) Aquarius (2011-2015): total

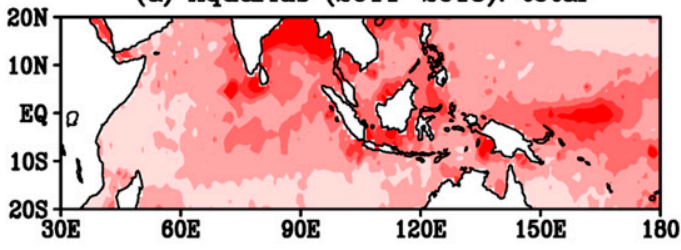

(c) CFSv2RAS: total

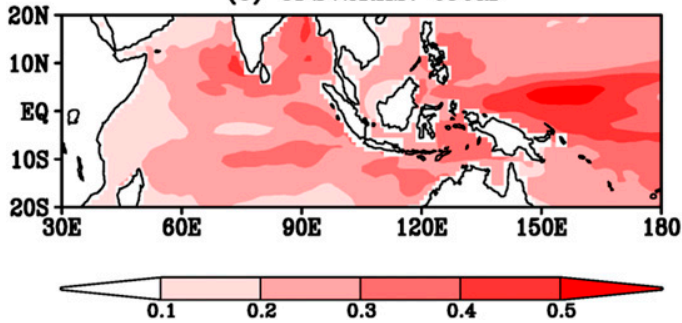

(b) Aquarius (2011-2015): 20-100-day

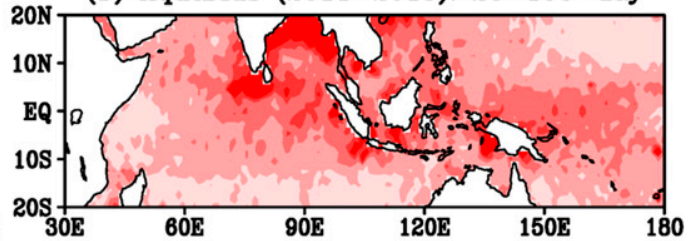

(d) CFSv2RAS: 20-100-day
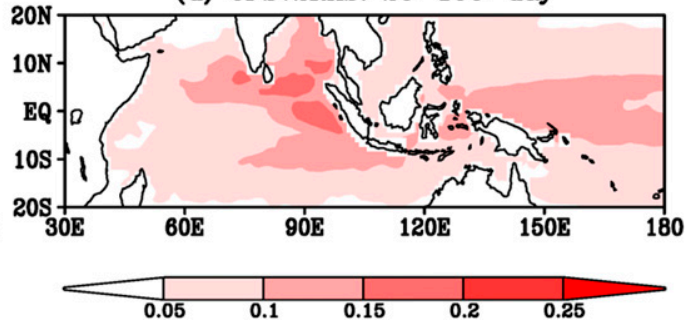

FIG. 2. Standard deviation of (a),(c) total nonseasonal (seasonal climatology removed) SSS anomalies (psu) and

(b),(d) intraseasonal (20-100 day filtered) SSS anomalies (psu) in (a),(b) Aquarius and (b),(d) CFSv2RAS.

lead time, but the application of third- or fifth-order polynomial fit shows negligible skill difference. For consistency, the same definition of anomalies is used for the Reference state (which also serves as the verification for the prediction experiments), which is done by reconstructing the Reference as if it were a forecast member for each initial time and target day. Both the Reference and predicted RMM indices are then normalized by the standard deviation of the Reference RMM indices. Following Lin et al. (2008), the bivariate anomaly correlation coefficient (ACC) and bivariate root-mean-square error (RMSE) are used to measure the MJO prediction skill in terms of RMM indices.

\section{MJO and intraseasonal SSS variability in CFSv2}

In this section, we briefly examine the MJO simulations in CFSv2 with the RAS convection scheme, and the analysis is based on the last 20 years of the Reference run with CFSv2. Figure 1 compares the composite MJO life cycle in CFSv2 with that in observations in terms of eight MJO phases (Wheeler and Hendon 2004). For each phase, the composite values are calculated as the average of 20-100-filtered anomalies for the days when $\mathrm{MJO}_{\text {pha }}$ is within this phase and $\mathrm{MJO}_{\mathrm{amp}}$ is greater than 1 . It is noted that there is one phase delay between the CFSv2 and observational composites. The phase mismatch, however, has no effect on our model validations, and is an artifact of the methodology applied in the calculation of the RMM index (i.e., EOF; Wheeler and Hendon 2004), which simply takes the first two leading orthogonal modes to represent the MJO. The two modes could represent phases 1 and 3 in one model and phases 2 and 4 in another, for example.

By comparing with observations (Figs. 1a,b), it is clear that CFSv2 realistically simulates the eastward propagation of convection and the phase relationship among precipitation, low-level winds, and SST associated with MJO (Figs. 1c,d). Particularly, the phase relationship between convections and SST is well captured: prior to the occurrence of convection (colors in Fig. 1d) SST (contours in Fig. 1d) tends to be warm, and after the passage of convection SST becomes cold. Our previous experiments (Zhu et al. 2017) also suggested that SST not only changes in a response to the MJO, but also plays an active role in MJO evolution. More details are available in Zhu et al. (2017).

Since SSS is a focus of this study, the simulation of intraseasonal SSS variability in CFSv2 is further validated against the Aquarius satellite observations (Lagerloef et al. 2010; Yueh 2013) for the tropical Indian Ocean and western tropical Pacific Ocean. Previously, the intraseasonal SSS variability in the Aquarius observations was analyzed by Guan et al. (2014) for the period of August 2011 to May 2013. In our validations, the whole Aquarius availability period is taken (August 2011-June 2015), and a comparison with Guan et al. (2014) is briefly discussed.

Figure 2 presents the standard deviation of total nonseasonal (relative to the seasonal cycle) and intraseasonal (20-100 day) SSS variability. By comparing with Guan et al. (2014; see their Fig. 1), it is evident that their analysis based on the shorter-period dataset captured a similar distribution of salinity variations as 


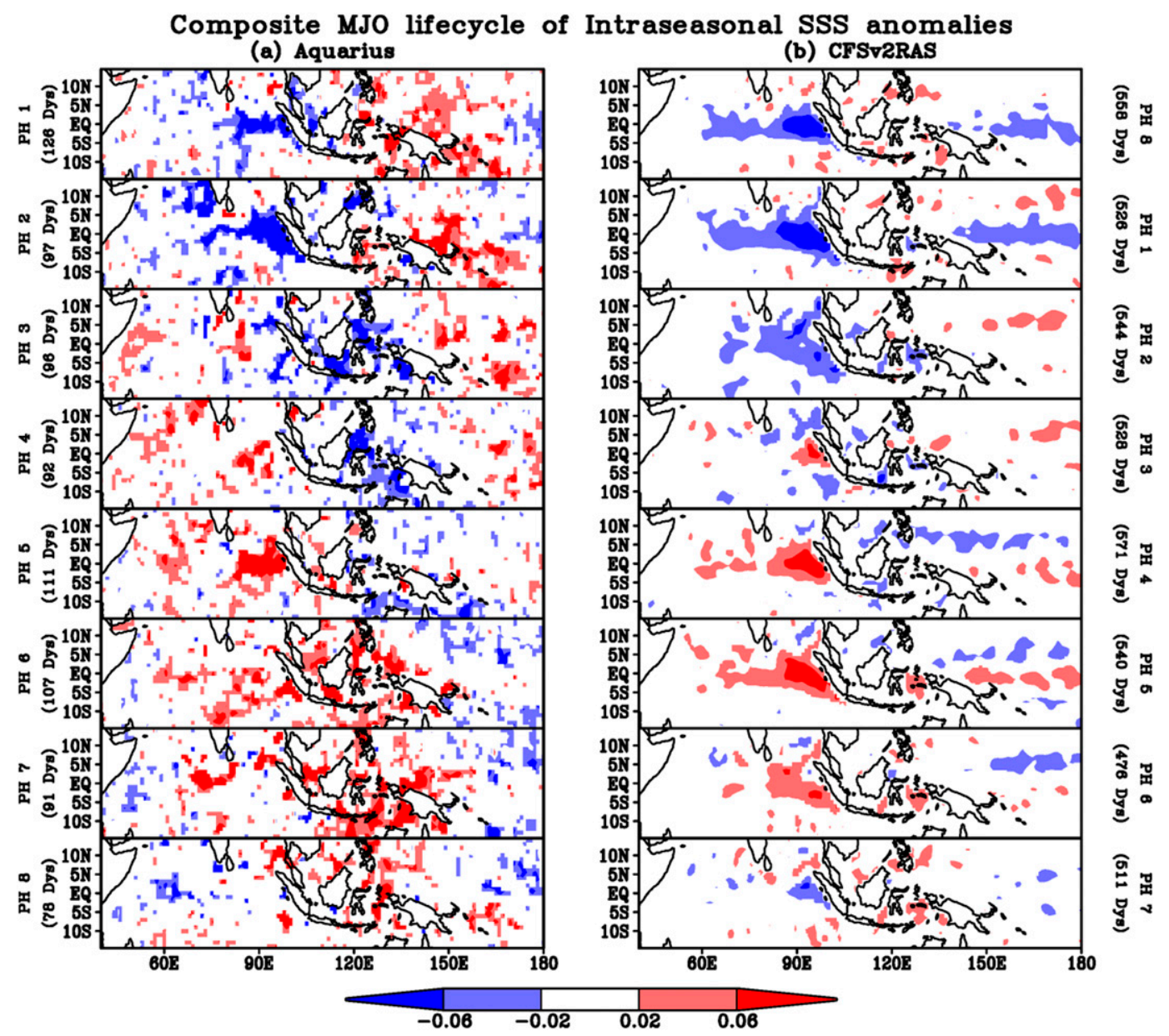

FIG. 3. Composite MJO life cycle of intraseasonal SSS anomalies (psu) in (a) Aquarius observations and (b) CFSv2RAS. For each phase, the composite value is the average of the days when the MJO is in a particular phase and the MJO amplitude is greater than 1, ranging from 78 days for phase 8 (476 days for phase 6) to 126 days for phase 1 (558 days for phase 8) in Aquarius (CFSv2RAS). Values in shadings are significant at the $90 \%$ level based on a two-tailed Student $t$ test.

here. In terms of total nonseasonal anomalies (Figs. 2a and 1a in Guan et al. 2014), large variations are present in the northern and equatorial Indian Ocean and the equatorial Pacific Ocean. A similar distribution with a smaller magnitude holds for the intraseasonal SSS variability [Figs. 2b and $1 b$ in Guan et al. (2014)]. In comparison with Aquarius SSS, the CFSv2 simulation captures the total nonseasonal SSS variation well in both distribution and magnitude (Fig. 2c). For the intraseasonal SSS anomaly, CFSv2 underestimates its magnitude, but captures the spatial distribution realistically (Fig. 2d).

Figure 3 examines the intraseasonal SSS evolution over the composite MJO cycle. The comparison between Fig. 3a herein and Guan et al. (2014; their Fig. 2) seems to suggest that an analysis based on a too short SSS record might include some uncertainties in deriving the MJO-related signal. With the almost 4-yr Aquarius SSS records (Fig. 3a), the MJO-related SSS presents a clear eastward-propagating signal, which is generally in phase of convection (not shown). In contrast, in the Guan et al. (2014) analysis based on 22 months of the Aquarius SSS record, the SSS propagating signal is not well defined. In CFSv2 (Fig. 3b), on the other hand, the eastward-propagating signal is well captured, even though the SSS variations, consistent with Fig. 2, are smaller than Aquarius.

In summary, the above validations suggest that the CFSv2 with the RAS convection scheme simulates the MJO quite realistically. For SSS, CFSv2 also well captures the MJO-related signal, even though its magnitude seems underestimated. Thus, we used CFSv2 as an example to explore the role of SSS feedback on MJO predictability. Reproducibility of upper ocean salinity 
Prediction Skill of RMM indices (5 Members)

(a) Correlation

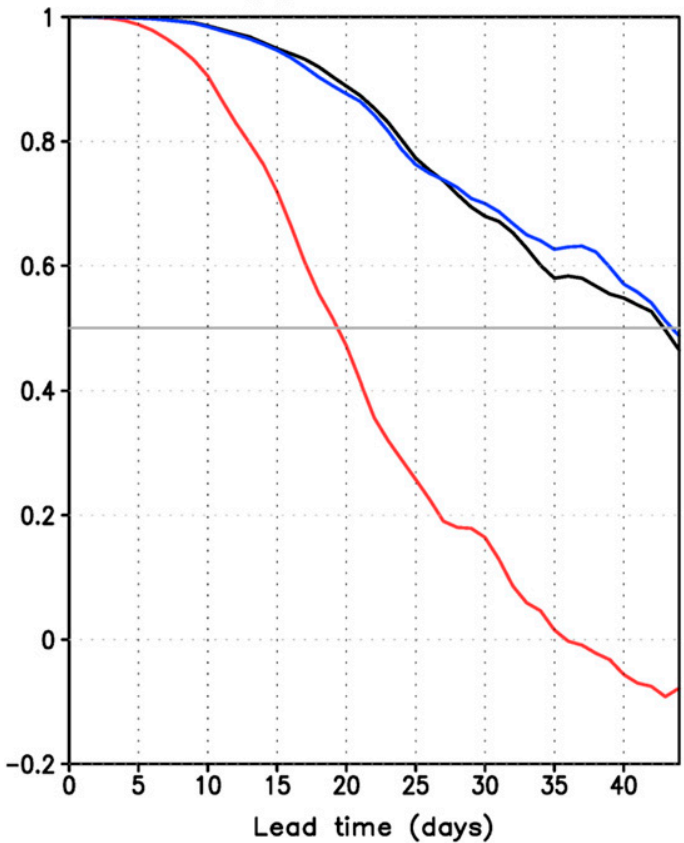

(b) RMSE

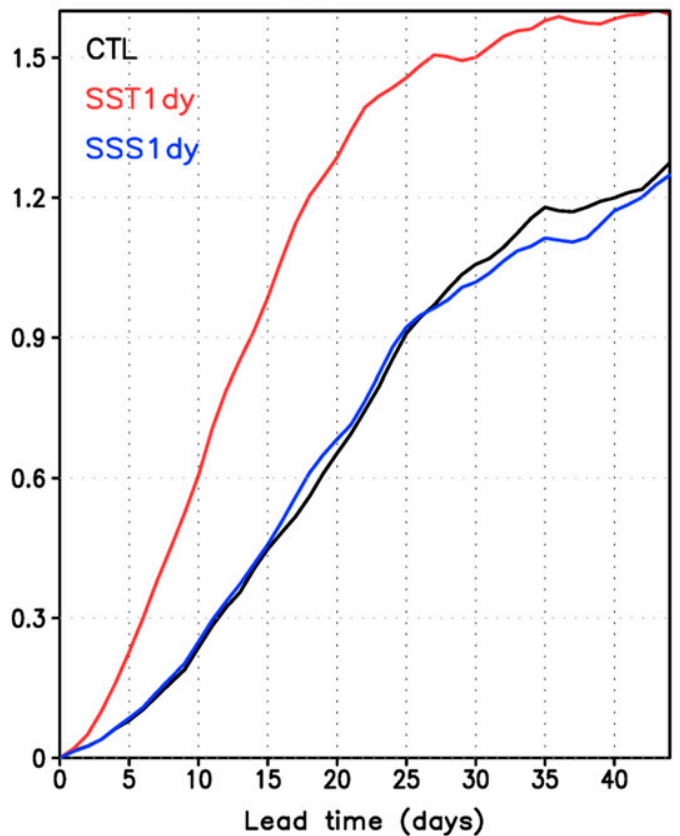

FIG. 4. (a) Bivariate anomaly correlation coefficient (ACC) and (b) bivariate root-mean-square error (RMSE) for predictions of CTL (black), SST1dy (red), and SSS1dy (blue). The horizontal line in (a) is 0.5 .

condition such as mixed layer depth (MLD) and BL thickness and the impacts on the MJO predictability are discussed in detail in section 5 .

\section{Predictability results}

Based on the CFSv2, three sets of predictability experiments (CTL, SST1dy, and SSS1dy) are conducted with the "perfect model" framework. As representative metrics of MJO overall prediction skill, Fig. 4 evaluates the bivariate ACC and bivariate RMSE between the Reference and predicted RMM indices (Wheeler and Hendon 2004) in the three experiments. By both measures, SSS1dy and CTL have comparable skill in predicting the MJO, and SST1dy has lower skill. The decay of skill in the CTL experiment suggests the MJO in CFSv2 is potentially predictable up to 44 days (when defined as the lead time when the ACC skill drops below 0.5). RMSE in CTL is generally less than 1.2 at lead times less than 40 days.

When the SST feedback is suppressed (i.e., the SST1dy experiment), the capability to predict the MJO is significantly reduced, with ACC decreasing to near zero and RMSE increasing to $\sim 1.6$ at day 36 . Consequently, SST1dy provides skillful MJO predictions only up to around 19 days (taking ACC of 0.5 as the threshold of skillful predictions). The marked skill reduction confirms that SST feedback plays an important role in MJO evolution, and thus its predictability (e.g., Fu et al. 2008; Pegion and Kirtman 2008). On the other hand, when the SSS feedback is suppressed (i.e., the SSS1dy experiment), negligible changes appear in the skill of MJO predictions relative to CTL. The comparison thus suggests that SSS feedback does not play a role in the MJO predictability in CFSv2. We note that SSS1dy experiments do include SST and MJO feedback and, relative to the CTL experiments, only the contribution of SSS variability on SST is suppressed. As suggested by the results, however, the role of SSS with regard to SST variability does not have an appreciable role with regard to MJO prediction skill.

To visualize the prediction differences among three experiments, predicted MJO evolutions for respective experiments are compared by looking at their composite precipitation, SST, and SSS anomalies. Figures 5 and 6 present the prediction anomalies with their initial states falling within phase 1 of MJO events (Wheeler and Hendon 2004), together with those in Reference. In Reference (Figs. 5a and 6a), active convection (colors) starts in the Indian Ocean, propagates through the Maritime Continent, and reaches the date line by day $\sim 30$. Prior to the occurrence of convections, SST 


\section{Composite Prate and SST \\ (starting from Initial Phase 1)}

(a) Reference

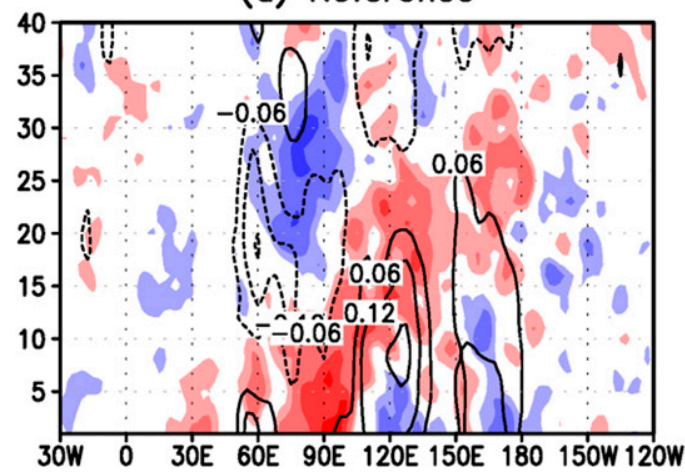

(c) SST1dy

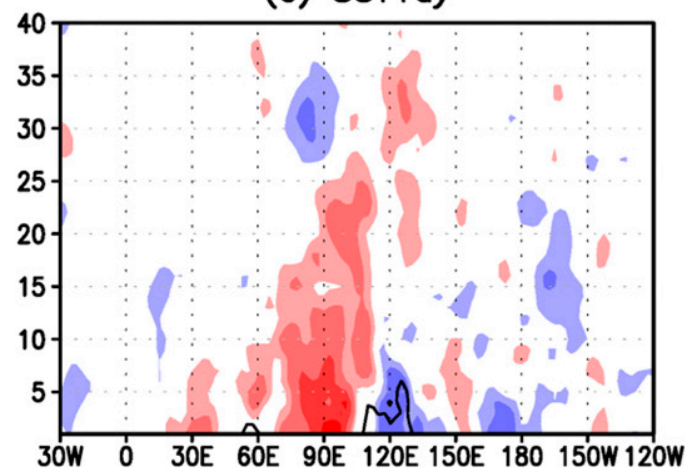

(b) CTL

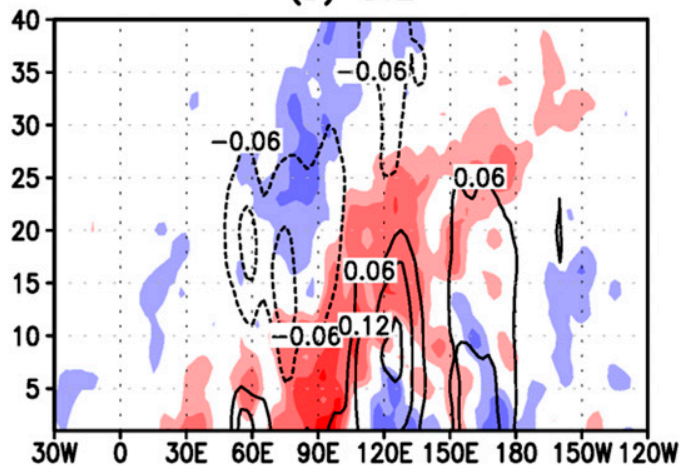

(d) SSS1dy

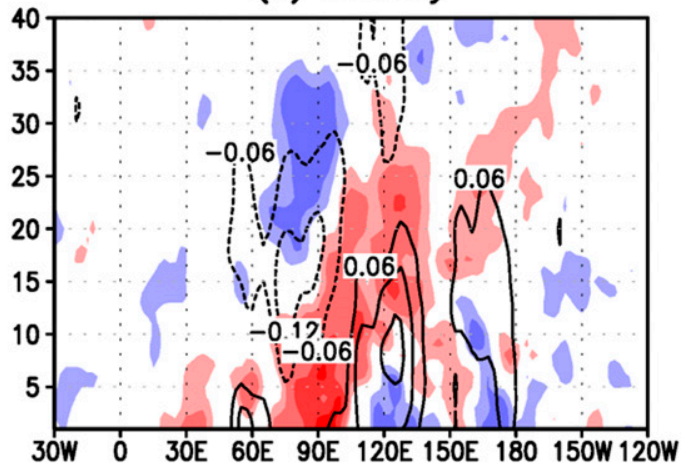

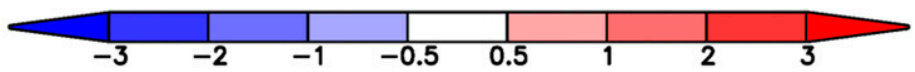

FIG. 5. The evolutions of composite precipitation ( $\mathrm{mm} \mathrm{day}^{-1}$; shadings) and SST $\left({ }^{\circ} \mathrm{C}\right.$; contours) averaged over $15^{\circ} \mathrm{S}-15^{\circ} \mathrm{N}$, starting from MJO initial phase 1 in (a) Reference simulations, and predictions of (b) CTL, (c) SST1dy, and (d) SSS1dy. For the composites, $30 \mathrm{MJO}$ events are picked when the MJO initial amplitude is larger than 1 and the MJO initial phase angle is within phase 1 (Wheeler and Hendon 2004). The $y$ axis represents time in days.

(contours in Fig. 5a) tends to be warm. After the passage of convection, SST becomes cold. The phase relationship between convection and SST is consistent with previous observational analysis (e.g., Krishnamurti et al. 1988; Shinoda et al. 1998; Woolnough et al. 2000; DeMott et al. 2015; Zhu et al. 2017), and our previous experiments (Zhu et al. 2017) have indicated an active role of SSTs in MJO evolution.

For SSS in CFSv2 (contours in Fig. 6a), the largest intraseasonal variations are in the central and eastern Indian Ocean, and generally follow the precipitation anomalies (colors in Figs. 5a and 6a), suggesting that in CFSv2 the MJO-related SSS variations in the Indian Ocean are largely controlled by evaporation-minusprecipitation $(E-P)$, consistent with observational diagnostics (Matthews et al. 2010; Grunseich et al. 2013). The SSS-precipitation relationship in the basin, however, is not at $1 / 4$-cycle lag, indicating some contributions from ocean dynamics (Guan et al. 2014). In addition, a secondary SSS variation (Fig. 5a) is present in the western Pacific (close to the west side of the date line), which seems to have little linkage with precipitation variations and is mainly driven by ocean dynamics (Matthews et al. 2010; Guan et al. 2014).

Overall, the results indicate that the MJO features in the Reference simulation are well predicted by the CTL experiment (Figs. 5b and 6b), suggesting a high predictability of the MJO in CFSv2. In SST1dy, as expected from its experimental design, there is little SST variation (contours in Fig. 5c); meanwhile, the eastward propagation of atmospheric convection is not apparent (or is much slower; colors in Figs. 5b and 6b). The prediction errors in convection confirm the important role SST feedback plays in maintaining the propagation of MJOrelated convective anomalies (Zhu et al. 2017) and thus in its predictions. For SSS, in SST1dy (contours in 


\section{Composite Prate and SSS (starting from Initial Phase 1)}

(a) Reference

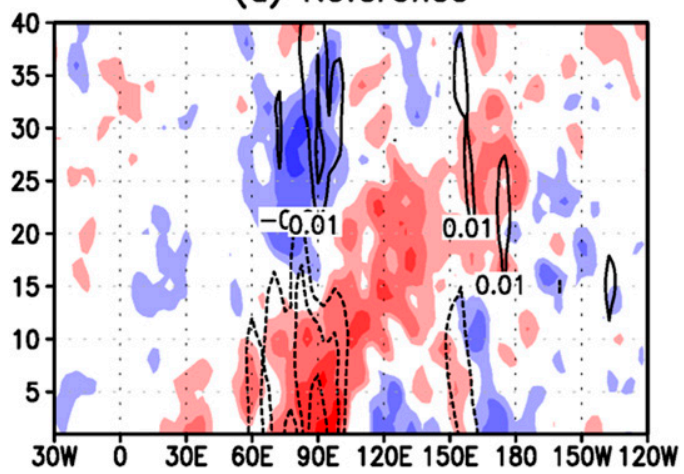

(c) SST1dy

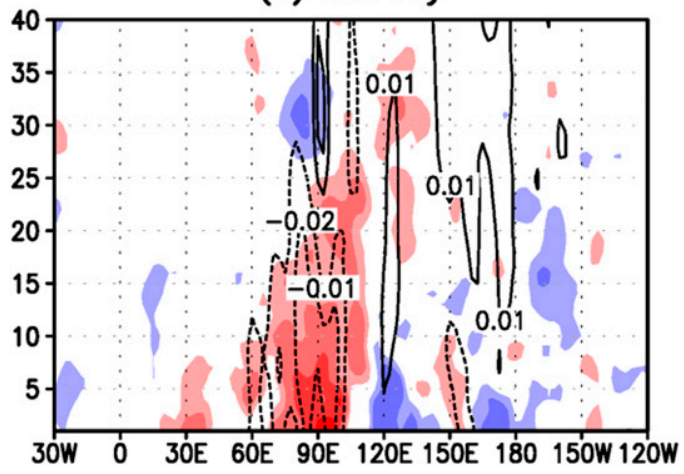

(b) CTL

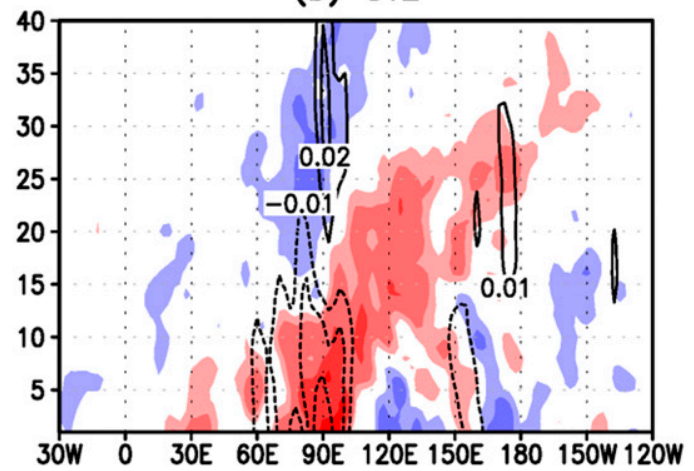

(d) SSS1dy

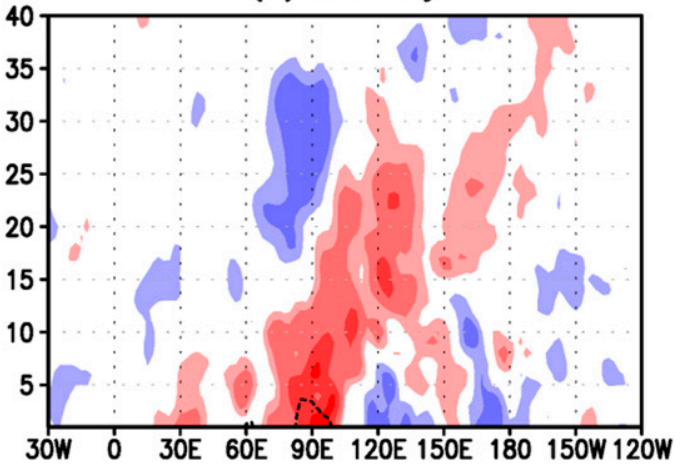

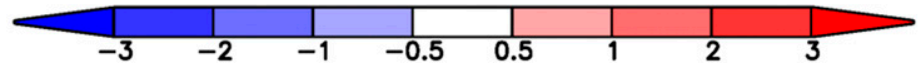

FIG. 6. As in Fig. 5, but for precipitation (mm day ${ }^{-1}$; shadings) and SSS (contours).

Fig. 6c), the SSS variations in the Indian Ocean are generally well predicted within the first 20 lead days, but not well afterward, which is related to prediction errors in precipitation (colors in Figs. 5c and 6c). In the western Pacific close to the west side of the date line (e.g., $150^{\circ} \mathrm{E}-$ $180^{\circ}$ ), no clear precipitation signal is predicted by SST1dy, but SSS anomalies are predicted to a certain level (contours in Fig. 6c), confirming the role of ocean dynamics in the intraseasonal SSS evolutions in the region as discussed above.

In SSS1dy, there are few SSS variations as expected (contours in Fig. 6d). On the other hand, the predictions of convection and SST (Fig. 5d) are comparable to those in CTL (Fig. 5b), featuring an eastward propagation as in Reference (Fig. 5a). The analyses are consistent with the skill evaluation in Fig. 4, suggesting that SSS plays a marginal role in MJO evolutions in CFSv2. The result is in contrast to previous suggestions (e.g., Zhang and McPhaden 2000; Drushka et al. 2014) and our original hypothesis that SSS plays an active role in MJO evolutions through modulating BL thickness and, further, SST. In addition, the above MJO differences among three sets of predictions can also be seen in the composites based on predictions starting from initial phase 4 of MJO (figures not shown), but with opposite anomalies.

As any possible impacts of SSS on the MJO must be bridged through SST, it is important to quantify how SST predictions in CFSv2 are influenced by the SSS nudging. Figures 7 and 8 compare the prediction skill of daily SST anomalies in three experiments by measures of anomaly correlation and RMSE, respectively. For each prediction experiment, correlation gradually decrease as lead time increases in all three experiments (Figs. 7), but RMSEs increase only in CTL (Fig. 8a) and SSS1dy (Fig. 8c), with small changes in SST1dy (Fig. 8b). In SST1dy, model SSTs are strongly nudged to a climatological state, and its SST variations are negligible (close to 0; e.g., Fig. 5c). Consequently, RMSE in SST1dy generally represents the variance of daily SSTs 


\section{Predictive Skill of Daily SSTA: Correlation}

(a) CTL
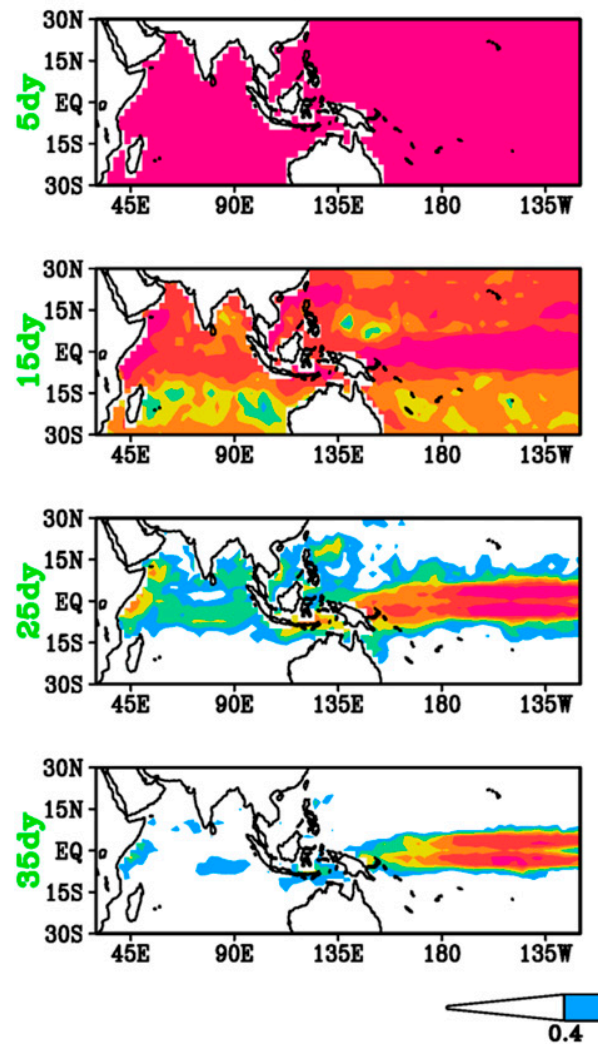

(b) SST1dy
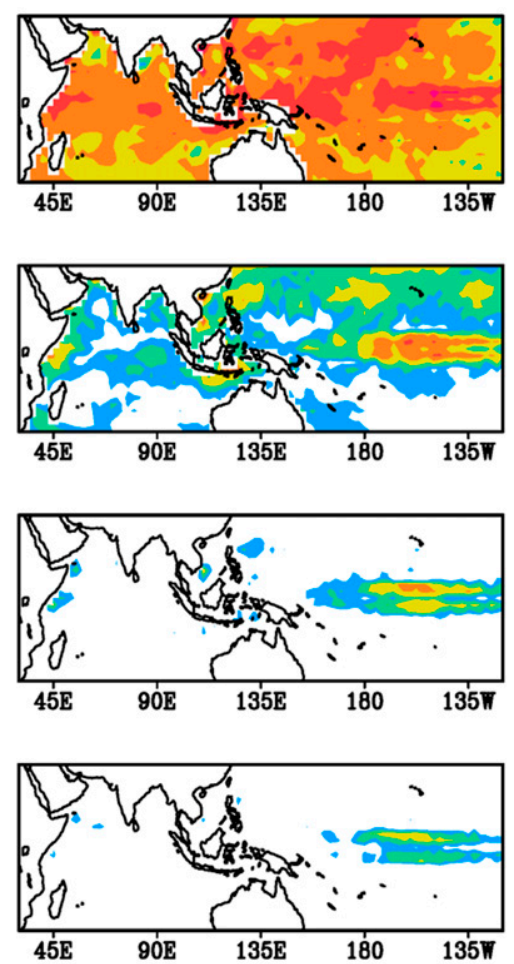

(c) Sss1dy
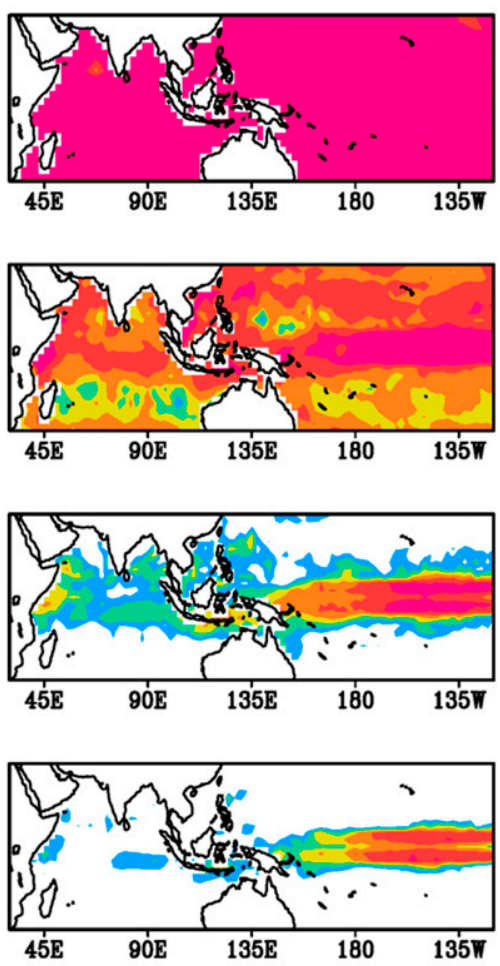

FIG. 7. Distribution of anomaly correlations of daily SST anomalies between Reference simulations and predictions by (a) CTL,

(b) SST1dy, and (c) SSS1dy, at (from top to bottom) 5, 15, 25, and 35 days of lead time.

in Reference, and thus remains almost the same at different lead times (Fig. 8b).

Comparing skill measures across experiments, as expected from the experimental design of SST1dy (SST variations are strongly suppressed), its daily SST anomalies show the worst prediction skill (Figs. 7b and 8 b) in comparison with CTL (Figs. 7a and 8a) and SSS1dy (Figs. 7c and 8c). The comparison between SSS1dy and CTL, on the other hand, suggests that the SST predictive skill does not exhibit a discernible degradation by the SSS nudging (Fig. 7a vs Fig. 7c; Fig. 8a vs Fig. 8c). In other words, the SSS nudging did not cause any discernible effects on SST evolutions in CFSv2, which explains why nudging SSS also exerts little effect on the MJO predictability in CFSv2 (Fig. 4).

\section{Discussion: BL simulation biases in CFSv2}

The above analyses of predictability experiments indicate that suppressing SSS feedback does not exert discernible effects on MJO predictability in CFSv2, which was further traced to no visible SST changes in association with the SSS variability. The next question is why allowing modulation in SSS did not bring changes in SST. Considering that the BL is an important mechanism for possible SSS influences on SST over the tropical Indian and western Pacific Oceans, in this section we assess the simulation of the BL in CFSv2. In this study, following Sprintall and Tomczak (1992), the isothermal layer depth (ILD) is defined as the depth at which temperature decreases by $0.5^{\circ} \mathrm{C}$ relative to the temperature at the 5-m depth (the model uppermost level), the MLD is defined by using a density difference from the surface (5-m depth) value that is equivalent to a decrease $\left(0.5^{\circ} \mathrm{C}\right)$ in temperature, and the BL thickness is defined as the difference between ILD and MLD. The part of analyses is again based on the last 20 years of the Reference run with CFSv2.

The simulation of climatological mean BL thickness is first evaluated in Figs. 9a and 9c. In observations (Fig. 9a), thick BL appears in the eastern equatorial Indian Ocean, the western equatorial Pacific Ocean, and the northwestern equatorial Atlantic Ocean, which are maintained by different mechanisms (Lukas and 


\section{Predictive Skill of Daily SSTA: RMSE}

(a) CTL
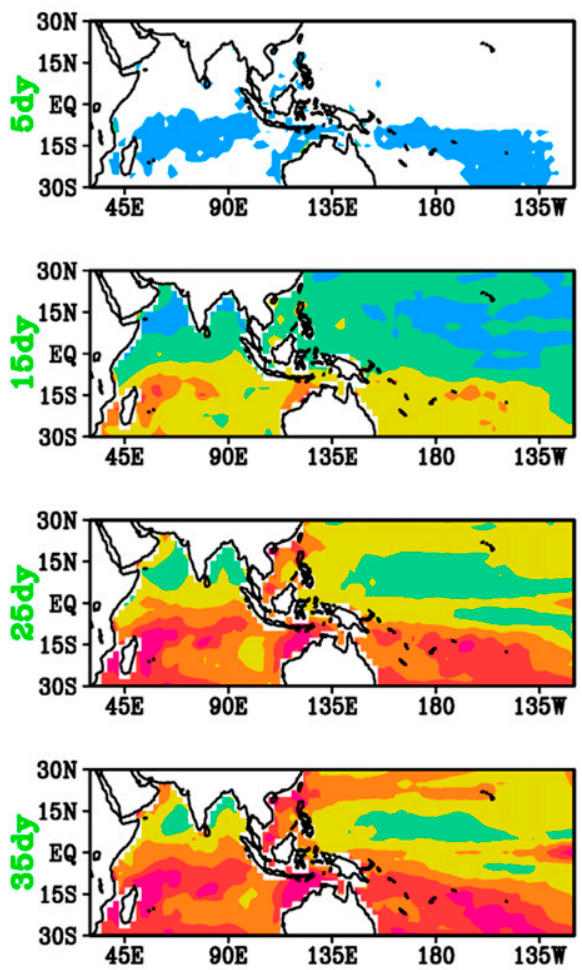

(b) SST1dy
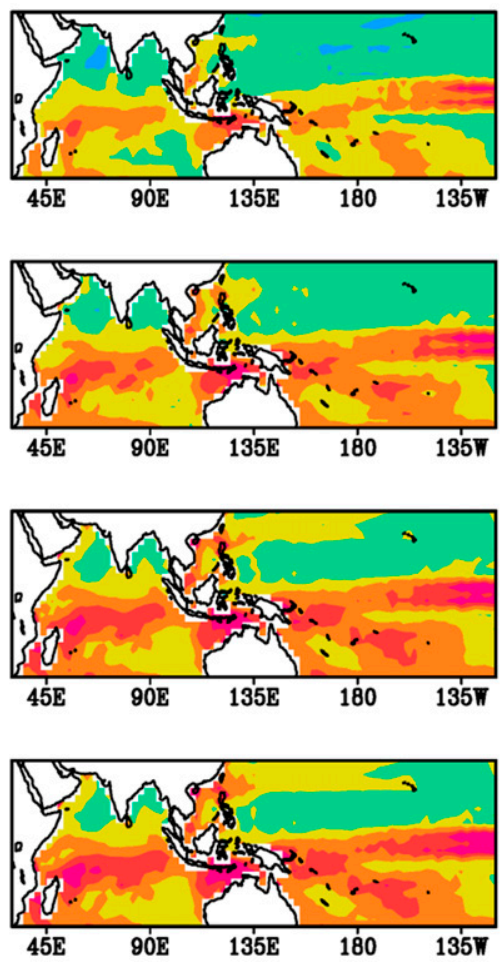

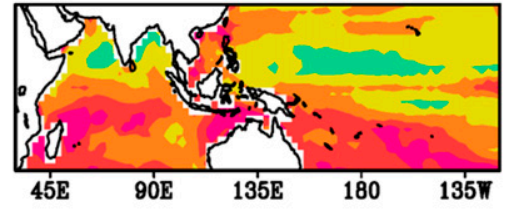

(c) SsS1dy
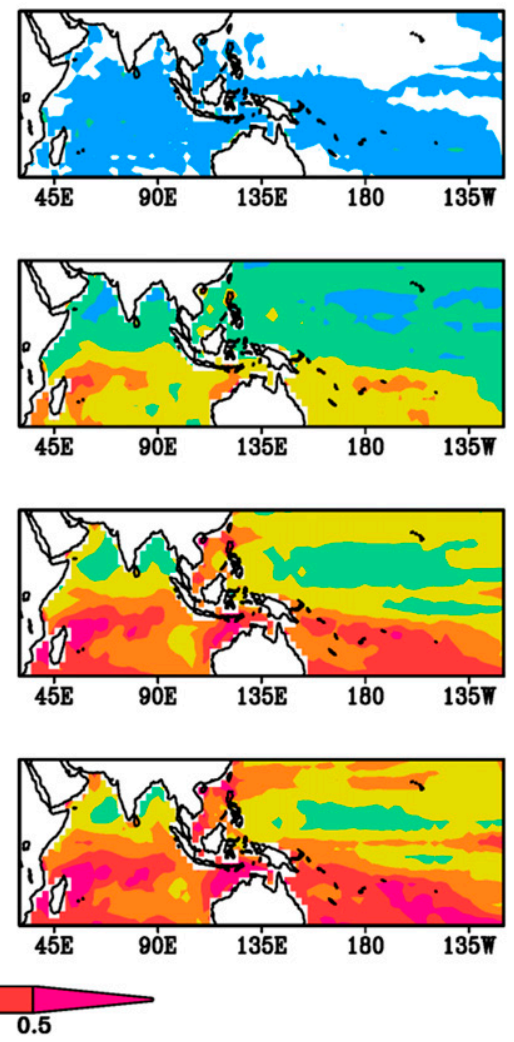

FIG. 8. As in Fig. 7, but for RMSEs $\left({ }^{\circ} \mathrm{C}\right)$.

Lindstrom 1991; Sprintall and Tomczak 1992). In CFSv2 (Fig. 9c), it is good to note that the climatological BL distribution is generally well captured. However, we also note that the simulated BL is too thin, only half of observed thickness. For a given atmospheric forcing, the thinner BL means a smaller BL effect on SST, which may degrade the SSS effect on MJO predictability. In addition, MLD is also somewhat deeper in CFSv2 (Fig. 9d) than in observations (Fig. 9b) in the eastern equatorial Indian Ocean and far western Pacific. The (a) BLT (IFREMER)

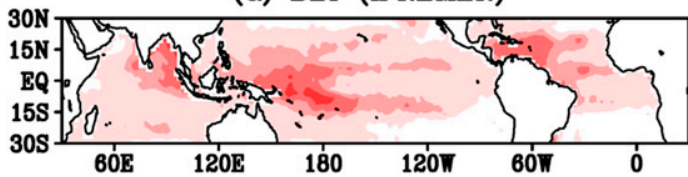

(c) BLT*2 (CFSv2RAS)

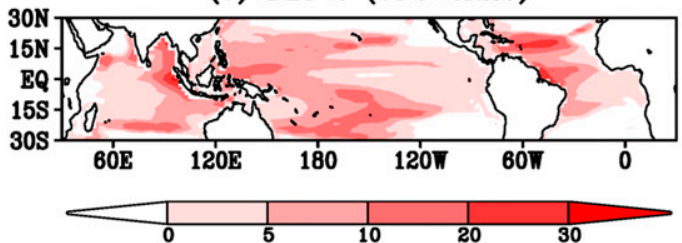

(b) MLD (IFREMER)

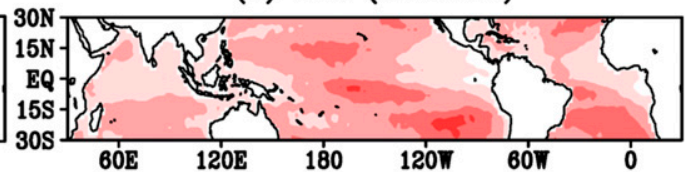

(d) MLD (CFSv2RAS)

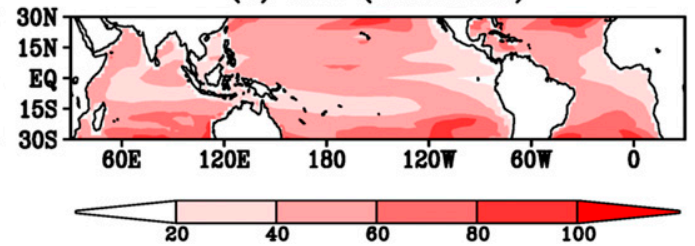

FIG. 9. Climatological mean (a),(c) barrier layer thickness (unit: m) and (b),(d) mixed layer depth (unit: m) distribution in (a),(b) observations produced by French Research Institute for Exploration of the Sea (IFREMER; http://www.ifremer.fr/cerweb/deboyer/mld) and (c),(d) CFSv2RAS. Note that values in (c) have been multiplied by a factor of 2 . 


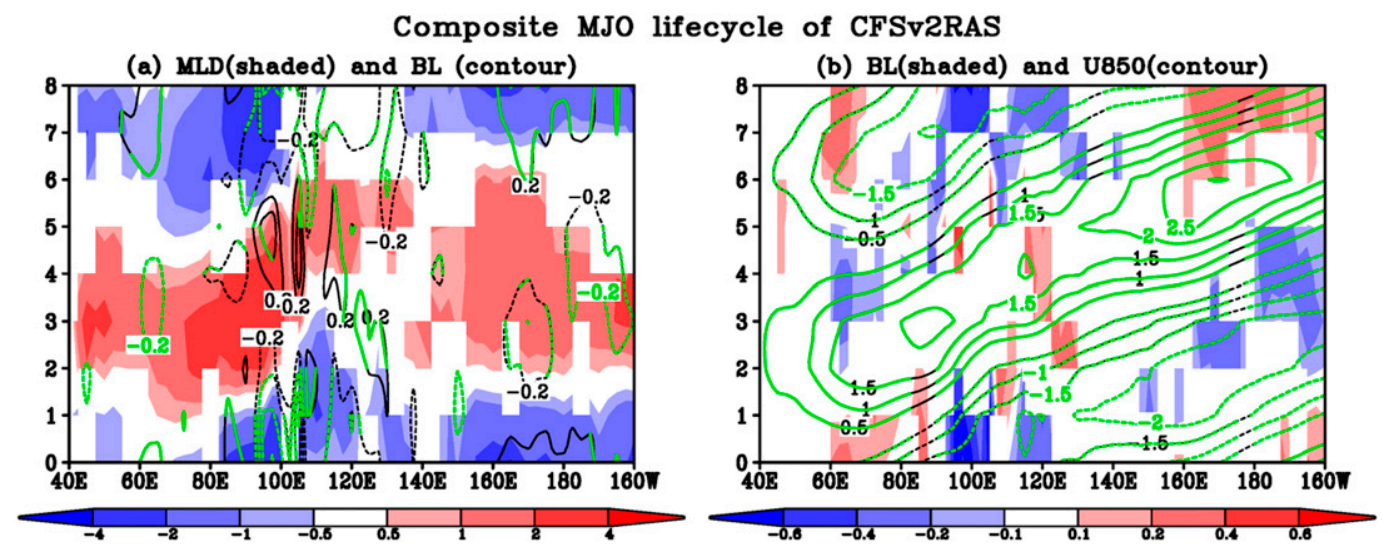

FIG. 10. Composite MJO life cycle in CFSv2RAS for intraseasonal anomalies of (a) MLD (m; shadings) and BL thickness ( $\mathrm{m}$; contours) and (b) BL thickness ( $\mathrm{m}$; shadings) and U850 ( $\mathrm{m} \mathrm{s}^{-1}$; contours). For each phase, the composite value is the average of the days when the MJO phase angle is within the phase and MJO amplitude is greater than 1, ranging from 476 days for phase 6 to 558 days for phase 8 . The $y$ axis represents MJO phases. Phase 8 is repeated as phase 0 for continuity of the display. Values in shadings and in green contours are significant at the $90 \%$ level based on a two-tailed Student $t$ test.

MLD bias may also cause a lack of salinity influence on MJO predictability through an underestimation of SST change in response to heat flux forcing.

Based on the analysis of variability, it is noted that the MJO-related BL variation is too small in CFSv2. For the simulation of MLD (colors in Fig. 10a), its intraseasonal variation east of $140^{\circ} \mathrm{E}$ is generally in accord with 850 hPa zonal wind (U850) and SST, suggesting that both stronger winds and surface cooling help to deepen the mixed layer from phase 1 over the eastern equatorial Indian to phase 5 over the western Pacific. However, since MLD and ILD (figure not shown) vary in tandem, the BL thickness between them does not change much during the course of the MJO cycle in CFSv2. The composite BL thickness anomaly in CFSv2 is generally less than $0.5 \mathrm{~m}$ (contours in Fig. 10a or colors in Fig. 10b) in association with the MJO, which is much smaller than a previous finding of Schiller and Godfrey (2003), who, based on a forced ocean general circulation model, reported a composite MJO BL thickness signal of around eight meters with even larger amplitudes in individual MJO events.

In addition, the intraseasonal BL-SST relationship seems not realistic in some regions. For example, Zhang and McPhaden (2000), based on a composite analysis of observed MJO events, demonstrated that the intraseasonal surface cooling at the WPEE (e.g., $0^{\circ}, 165^{\circ} \mathrm{E}$ ) is partially contributed by the thinning of $\mathrm{BL}$, suggesting an active role of $\mathrm{BL}$ in MJO evolution. In CFSv2, in contrast, the cooling (Fig. 11e) corresponds to the thickening of BL (Fig. 11d). In fact, the BL-U850 relationship (Figs. 10b, 11b,d) seems to suggest that the $\mathrm{BL}$ thickening is a response to anomalous westerlies at the WPEE as suggested by Cronin and McPhaden (2002). The inconsistency might explain why SST in CFSv2 is less sensitive to BL variations.

In summary, the above analyses indicate that the current version of CFSv2 presents significant biases in simulating $\mathrm{BL}$ in the tropical oceans, including too thin a climatological thickness, too small intraseasonal variations, and an unrealistic intraseasonal BL-SST relationship. While our predictability experiments with CFSv2 illustrate negligible effects on MJO predictability from SSS, the possibility could not be rejected that SSS does play a role in MJO predictability as suggested by previous studies (e.g., Zhang and McPhaden 2000; Drushka et al. 2014; Guan et al. 2014; Horii et al. 2016), but the current model (particularly the subsurface ocean process) is not good enough to capture the relevant physics and signal. In the future, the question is definitely worthy of a revisit once climate models are significantly improved with a realistic BL simulation.

\section{Conclusions}

In this study, the MJO simulation (particularly its associated SSS simulation) in CFSv2 is first briefly validated against observations. This analysis suggests that the CFSv2 with the RAS convection scheme simulates the MJO quite realistically. Especially, compared with the Aquarius SSS observations, the CFSv2 has good fidelity in simulating the MJO-related SSS signal.

Further, to explore the role of SSS feedback in MJO predictability, three sets of predictability experiments 


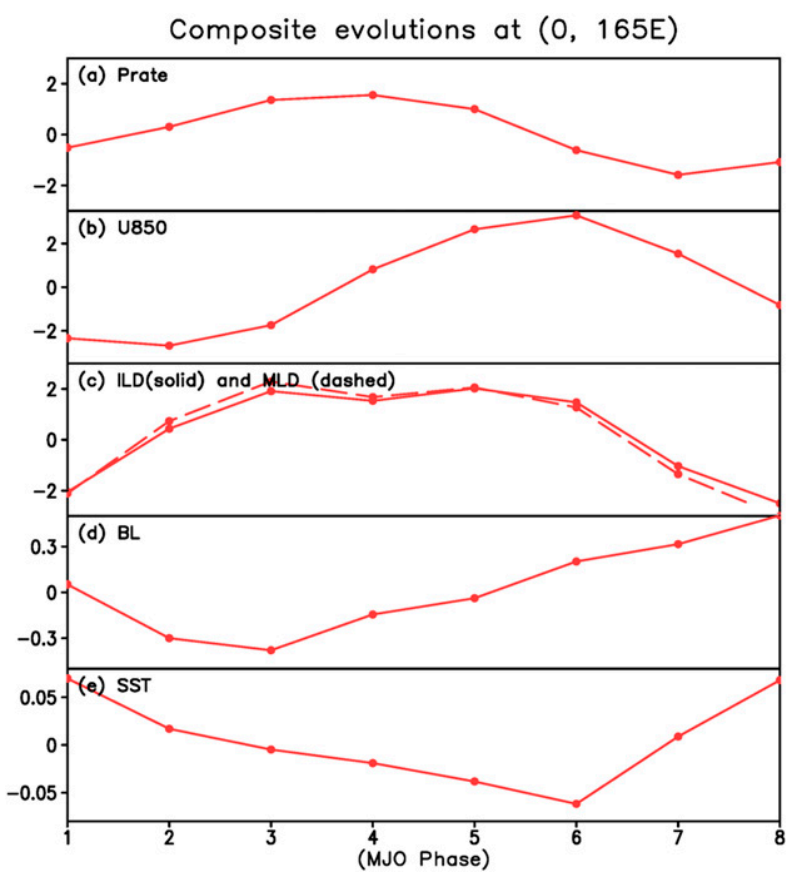

FIG. 11. Composite MJO life cycle at $\left(0^{\circ}, 165^{\circ} \mathrm{E}\right)$ in Reference (CFSv2RAS) simulations for intraseasonal anomalies of (a) precipitation $\left(\mathrm{mm} \mathrm{day}^{-1}\right)$, (b) U850 $\left(\mathrm{m} \mathrm{s}^{-1}\right)$, (c) ILD (m; solid) and MLD (m; dashed), (d) BL thickness (m), and (e) SST $\left({ }^{\circ} \mathrm{C}\right)$. For each phase, the composite value is the average of the days when the MJO phase angle is within the phase and MJO amplitude is greater than 1.

were conducted to predict MJO events in CFSv2. The first one is conducted for an estimation of MJO predictability in CFSv2, and the other two are performed with model SSS and SST nudged to climatological states during forecasts, respectively. The comparison of the experiments indicates that SSS feedback exerts negligible influences on MJO predictability in CFSv2, in contrast to large impacts from SST feedback. The minimal role of SSS in MJO predictability is further traced to marginal changes in SST in association with the suppression of SSS feedback.

To understand why SST does not change as a result of SSS modulations, we explored the simulation of the BL in CFSv2, which is an important "bridge" for possible SSS influences on SST over the tropical Indian and western Pacific Oceans. It was found that significant BL simulation biases exist in the tropical oceans (e.g., too thin a climatological thickness, too small intraseasonal variations, and an unrealistic intraseasonal BL-SST relationship). Thus, it is possible that SSS does play a role in MJO predictability, but its effect is not as strong as that associated with SST and the current model is not realistic enough to capture such signal. Considering this possibility, more experiments with diverse models (particularly those with more realistic BL simulations) should be encouraged to revisit the hypothesis that salinity might be able to affect MJO predictability through its role in the BL and SST. Following the path, a new version of CFSv2 with 1-m vertical resolution in the upper ocean (Ge et al. 2017; Zhang et al. 2019) is being applied for experiments. We expect that the new version might simulate the BL more realistically and will provide further assessment of the role of SSS on MJO variability.

In addition, previous studies (e.g., Schiller and Godfrey 2003; Drushka et al. 2014) have suggested that the BL thickness variance over individual events may be considerably larger than the composite. In future, we plan to analyze some MJO events in model simulations with stronger BL signal and realistic SST-BL relationship, and conduct predictability experiments based on them. Such an event-dependent salinity effect was actually identified in a previous ENSO predictability study (Zhu et al. 2014).

Acknowledgments. The authors thank Drs. Raghu G. Murtugudde, Tony Lee, Pingping Xie, and Li Ren for their comments. We are also grateful to insightful comments from Dr. Annamalai and anomalous reviewers. The work is supported by the NASA Ocean Salinity Science Team Grant NNX17AK09G. We also thank NOAA's Climate Program Office for their support through the Modeling, Analysis, Predictions, and Projections (MAPP) and Climate Variability and Predictability (CVP) programs. This study was partially supported by NOAA Grant NA14NES4320003 (Cooperative Institute for Climate and Satellites-CICS) at the University of Maryland/ESSIC.

\section{REFERENCES}

Annamalai, H., R. Murtugudde, J. Potemra, S. Xie, P. Liu, and B. Wang, 2003: Coupled dynamics over the Indian Ocean: Spring initiation of the zonal mode. Deep-Sea Res. II, 50, 23052330, https://doi.org/10.1016/S0967-0645(03)00058-4.

Ballabrera-Poy, J., R. Murtugudde, and A. J. Busalacchi, 2002: On the potential role of sea surface salinity observations on ENSO predictions. J. Geophys. Res., 107, 8007, https://doi.org/10.1029/ 2001JC000834.

Cravatte, S., and Coauthors, 2016: First Report of TPOS 2020: December 2016. GOOS-215, TPOS 2020, 200 pp., TPOS2020.org/first-report/.

Cronin, M. F., and M. J. McPhaden, 2002: Barrier layer formation during westerly wind bursts. J. Geophys. Res., 107, 8020, https://doi.org/10.1029/2001JC001171.

Delcroix, T., and M. J. McPhaden, 2002: Interannual sea surface salinity and temperature changes in the western Pacific warm pool during 1992-2000. J. Geophys. Res., 107, 8002, https:// doi.org/10.1029/2001JC000862.

DeMott, C. A., N. P. Klingaman, and S. J. Woolnough, 2015: Atmosphere-ocean coupled processes in the Madden-Julian oscillation. Rev. Geophys., 53, 1099-1154, https://doi.org/ 10.1002/2014RG000478.

Drushka, K., J. Sprintall, S. Gille, and S. Wijffels, 2012: In situ observations of Madden-Julian oscillation mixed layer dynamics 
in the Indian and western Pacific Oceans. J. Climate, 25, 23062328, https://doi.org/10.1175/JCLI-D-11-00203.1.

,$- \ldots$, and -2014 : Subseasonal variations in salinity and barrier-layer thickness in the eastern equatorial Indian Ocean. J. Geophys. Res. Oceans, 119, 805-823, https://doi.org/10.1002/ 2013JC009422.

Font, J., and Coauthors, 2013: SMOS first data analysis for sea surface salinity determination. Int. J. Remote Sens., 34, 36543670, https://doi.org/10.1080/01431161.2012.716541.

Fu, X., B. Yang, Q. Bao, and B. Wang, 2008: Sea surface temperature feedback extends the predictability of tropical intraseasonal oscillation. Mon. Wea. Rev., 136, 577-597, https:// doi.org/10.1175/2007MWR2172.1.

Ge, X., W. Wang, A. Kumar, and Y. Zhang, 2017: Simulations of SST diurnal and intraseasonal variability in an oceanic general circulation model. J. Climate, 30, 3963-3978, https://doi.org/ 10.1175/JCLI-D-16-0689.1.

Grunseich, G., B. Subrahmanyam, and B. Wang, 2013: The Madden-Julian oscillation detected in Aquarius salinity observations. Geophys. Res. Lett., 40, 5461-5466, https://doi.org/ 10.1002/2013GL058173.

Guan, B., T. Lee, D. J. Halkides, and D. E. Waliser, 2014: Aquarius surface salinity and the Madden-Julian oscillation: The role of salinity in surface layer density and potential energy. Geophys. Res. Lett., 41, 2858-2869, https://doi.org/10.1002/ 2014 GL059704.

Hendon, H. H., 2003: Indonesian rainfall variability: Impacts of ENSO and local air-sea interaction. J. Climate, 16, 1775-1790, https://doi.org/10.1175/1520-0442(2003)016<1775:IRVIOE > 2.0.CO;2.

Horii, T., I. Ueki, K. Ando, T. Hasegawa, K. Mizuno, and A. Seiki, 2016: Impact of intraseasonal salinity variations on sea surface temperature in the eastern equatorial Indian Ocean. J. Oceanogr., 72, 313-326, https://doi.org/10.1007/s10872-015-0337-x.

$\mathrm{Hu}, \mathrm{S}$., and J. Sprintall, 2016: Interannual variability of the Indonesian Throughflow: The salinity effect. J. Geophys. Res. Oceans, 121, 2596-2615, https://doi.org/10.1002/2015JC011495.

Joyce, R. J., J. E. Janowiak, P. A. Arkin, and P. Xie, 2004: CMORPH: A method that produces global precipitation estimates from passive microwave and infrared data at high spatial and temporal resolution. J. Hydrometeor., 5, 487-503, https://doi.org/10.1175/1525-7541(2004)005<0487: CAMTPG $>2.0 . \mathrm{CO} ; 2$.

Krishnamurti, T. N., D. K. Oosterhof, and A. V. Mehta, 1988: Airsea interaction on the time scale of 30-50 days. J. Atmos. Sci., 45, 1304-1322, https://doi.org/10.1175/1520-0469(1988)045<1304: AIOTTS $>2.0 . \mathrm{CO} ; 2$.

Lagerloef, G., and Coauthors, 2010: Aquarius/SAC-D mission: Designed to meet the salinity remote-sensing challenge. Oceanography, 21, 68-81, https://doi.org/10.5670/oceanog.2008.68.

Lengaigne, M., E. Guilyardi, J. P. Boulanger, C. Menkes, P. Delecluse, P. Inness, J. Cole, and J. Slingo, 2004: Triggering of El Niño by westerly wind events in a coupled general circulation model. Climate Dyn., 23, 601-620, https://doi.org/ 10.1007/s00382-004-0457-2.

Li, Y., and W. Han, 2016: Causes for intraseasonal sea surface salinity variability in the western tropical Pacific Ocean and its seasonality. J. Geophys. Res. Oceans, 121, 85-103, https:// doi.org/10.1002/2015JC011413.

, _ _ and T. Lee, 2015: Intraseasonal sea surface salinity variability in the equatorial Indo-Pacific Ocean induced by Madden-Julian oscillations. J. Geophys. Res. Oceans, 120, 2233-2258, https://doi.org/10.1002/2014JC010647.
Lin, H., G. Brunet, and J. Derome, 2008: Forecast skill of the Madden-Julian oscillation in two Canadian atmospheric models. Mon. Wea. Rev., 136, 4130-4149, https://doi.org/ 10.1175/2008MWR2459.1.

Lukas, R., and E. Lindstrom, 1991: The mixed layer of the western equatorial Pacific Ocean. J. Geophys. Res., 96, 3343-3357, https://doi.org/10.1029/90JC01951.

Maes, C., J. Picaut, and S. Belamari, 2005: Importance of the salinity barrier layer for the buildup of El Niño. J. Climate, 18, 104-118, https://doi.org/10.1175/JCLI-3214.1.

Masson, S., C. Menkes, P. Delecluse, and J.-P. Boulanger, 2003: Impacts of salinity on the eastern Indian Ocean during the termination of the fall Wyrtki jet. J. Geophys. Res., 108, 3067, https://doi.org/10.1029/2001JC000833.

Matthews, A. J., P. Singhruck, and K. J. Heywood, 2010: Ocean temperature and salinity components of the Madden-Julian oscillation observed by Argo floats. Climate Dyn., 35, 11491168, https://doi.org/10.1007/s00382-009-0631-7.

McPhaden, M. J., 2004: Evolution of the 2002/03 El Niño. Bull. Amer. Meteor. Soc., 85, 677-695, https://doi.org/10.1175/BAMS-855-677.

Moorthi, S., and M. J. Suarez, 1992: Relaxed Arakawa-Schubert: A parameterization of moist convection for general circulation models. Mon. Wea. Rev., 120, 978-1002, https://doi.org/ 10.1175/1520-0493(1992)120<0978:RASAPO > 2.0.CO;2.

$\longrightarrow$, and - 1999: Documentation of version 2 of relaxed Arakawa-Schubert cumulus parameterization with convective downdrafts. NOAA Office Note 99-01, 44 pp.

Murtugudde, R., and A. J. Busalacchi, 1998: Salinity effects in tropical oceans. J. Geophys. Res., 103, 3283-3300, https:// doi.org/10.1029/97JC02438.

—, and —, 1999: Interannual variability of the dynamics and thermodynamics of the Indian Ocean. J. Climate, 12, 2300-2326, https:// doi.org/10.1175/1520-0442(1999)012<2300:IVOTDA > 2.0.CO;2.

- J. Beauchamp, C. McClain, M. Lewis, and A. Busalacchi, 2002: Effects of penetrative radiation on the upper tropical ocean circulation. J. Climate, 15, 470-486, https://doi.org/ 10.1175/1520-0442(2002)015<0470:EOPROT > 2.0.CO;2.

Pan, H.-L., and W.-S. Wu, 1995: Implementing a mass flux convection parameterization package for the NMC mediumrange forecast model. NMC Office Note 409, $39 \mathrm{pp}$.

Pegion, K., and B. Kirtman, 2008: The impact of air-sea interactions on the predictability of the tropical intraseasonal oscillation. J. Climate, 21, 5870-5886, https://doi.org/10.1175/ 2008JCLI2209.1.

Picaut, J., M. Ioualalen, C. Menkes, T. Delcroix, and M. J. McPhaden, 1996: Mechanism of the zonal displacements of the Pacific warm pool: Implications for ENSO. Science, 274, 1486-1489, https://doi.org/10.1126/science.274.5292.1486.

Qiu, Y., W. Cai, L. Li, and X. Guo, 2012: Argo profiles variability of barrier layer in the tropical Indian Ocean and its relationship with the Indian Ocean dipole. Geophys. Res. Lett., 39, L08605, https://doi.org/10.1029/2012GL051441.

Reynolds, R. W., T. M. Smith, C. Liu, D. B. Chelton, K. S. Casey, and M. G. Schlax, 2007: Daily high-resolution-blended analyses for sea surface temperature. J. Climate, 20, 5473-5496, https://doi.org/10.1175/2007JCLI1824.1.

Roemmich, D., M. Morris, W. R. Young, and J.-R. Donguy, 1994: Fresh equatorial jets. J. Phys. Oceanogr., 24, 540-558, https:// doi.org/10.1175/1520-0485(1994)024<0540:FEJ >2.0.CO;2.

Saha, S., and Coauthors, 2010: The NCEP Climate Forecast System Reanalysis. Bull. Amer. Meteor. Soc., 91, 1015-1057, https:// doi.org/10.1175/2010BAMS3001.1. 
and Coauthors, 2014: The NCEP Climate Forecast System version 2. J. Climate, 27, 2185-2208, https://doi.org/10.1175/ JCLI-D-12-00823.1.

Schiller, A., and J. S. Godfrey, 2003: Indian Ocean intraseasonal variability in an ocean general circulation model. J. Climate, 16, 21-39, https://doi.org/10.1175/1520-0442(2003)016<0021: IOIVIA $>2.0 . \mathrm{CO} ; 2$.

Schmitt, R. W., 2008: Salinity and the global water cycle. Oceanography, 21, 12-19, https://doi.org/10.5670/oceanog.2008.63.

Seo, H., S. P. Xie, R. Murtugudde, M. Jochum, and A. J. Miller, 2009: Seasonal effects of Indian Ocean freshwater forcing in a regional coupled model. J. Climate, 22, 6577-6596, https:// doi.org/10.1175/2009JCLI2990.1.

Shinoda, T., H. H. Hendon, and J. Glick, 1998: Intraseasonal variability of surface fluxes and sea surface temperature in the tropical western Pacific and Indian Oceans. J. Climate, 11, 1685-1702, https://doi.org/10.1175/1520-0442(1998)011<1685: IVOSFA $>2.0 . \mathrm{CO} ; 2$.

Sprintall, J., and M. Tomczak, 1992: Evidence of the barrier layer in the surface layer of the tropics. J. Geophys. Res., 97, 73057316, https://doi.org/10.1029/92JC00407.

Wheeler, M. C., and H. H. Hendon, 2004: An all-season real-time multivariate MJO index: Development of an index for monitoring and prediction. Mon. Wea. Rev., 132, 1917-1932, https://doi.org/ 10.1175/1520-0493(2004)132<1917:AARMMI>2.0.CO;2.
Woolnough, S. J., J. M. Slingo, and B. J. Hoskins, 2000: The relationship between convection and sea surface temperature on intraseasonal timescales. J. Climate, 13, 2086-2104, https://doi.org/10.1175/15200442(2000)013<2086:TRBCAS>2.0.CO;2.

Yoneyama, K., C. Zhang, and C. N. Long, 2013: Tracking pulses of the Madden-Julian oscillation. Bull. Amer. Meteor. Soc., 94, 1871-1891, https://doi.org/10.1175/BAMS-D-12-00157.1.

Yueh, S., 2013: Aquarius CAP algorithm and data user guide, version 2.0. Jet Propulsion Laboratory, California Institute of Technology, $20 \mathrm{pp}$.

Zhang, C., and M. J. McPhaden, 2000: Intraseasonal surface cooling in the equatorial western Pacific. J. Climate, 13, 2261-2276, https:// doi.org/10.1175/1520-0442(2000)013<2261:ISCITE >2.0.CO;2.

Zhang, Y., M.-P. Hung, W. Wang, and A. Kumar, 2019: Role of SST feedback in the prediction of the boreal summer monsoon intraseasonal oscillation. Climate Dyn., https:/doi.org/10.1007/ s00382-019-04753-w.

Zhu, J., B. Huang, R.-H. Zhang, Z.-Z. Hu, A. Kumar, M. A. Balmaseda, L. Marx, and J. L. Kinter III, 2014: Salinity anomaly as a trigger for ENSO events. Sci. Rep., 4, 6821, https://doi.org/10.1038/srep06821.

- W. Wang, and A. Kumar, 2017: Simulations of MJO propagation across the Maritime Continent: Impacts of SST feedback. J. Climate, 30, 1689-1704, https://doi.org/ 10.1175/JCLI-D-16-0367.1. 